\title{
A Decoupling Control Strategy for Multilayer Register System in Printed Electronic Equipment
}

\author{
Shanhui Liu, Bingzheng Yin, Li'e Ma, Hongwei Xu, and Geshun Zhu \\ Faculty of Printing, Packaging Engineering and Digital Media Technology, Xian University of Technology, No. 5, \\ Jinhua South Road, Xian 710048, China \\ Correspondence should be addressed to Shanhui Liu; shanhuiliu@xaut.edu.cn
}

Received 30 June 2016; Revised 13 August 2016; Accepted 16 August 2016

Academic Editor: Valentina E. Balas

Copyright (C) 2016 Shanhui Liu et al. This is an open access article distributed under the Creative Commons Attribution License, which permits unrestricted use, distribution, and reproduction in any medium, provided the original work is properly cited.

Register accuracy is an important index to evaluate the quality of electronic products printed by gravure printed electronic equipment. However, the complex relationships of multilayer register system make the problem of decoupling control difficult to be solved, which has limited the improvement of register accuracy for the gravure printed electronic equipment. Therefore, this paper presents an integrated decoupling control strategy based on feedforward control and active disturbance rejection control (ADRC) to solve the strong coupling, strong interference, and time-delay problems of multilayer register system. First of all, a coupling and nonlinear model is established according to the multilayer register working principle in gravure printing, and then a linear model of the register system is derived based on the perturbation method. Secondly, according to the linear model, a decoupling control strategy is designed based on feedforward control and ADRC for the multilayer register system. Finally, the results of computer simulation show that the proposed control methodology can realize a decoupling control and has good control performance for multilayer register system.

\section{Introduction}

Roll-to-roll (R2R) gravure printing machine is considered one of the highest throughput printed electronic equipment for manufacturing disposable and flexible electronic devices on flexible substrates at a low cost [1]. Register accuracy is an important index to evaluate the quality of printed electronic products. Unfortunately, because of the characteristics of multilayer register system including multi-input multioutput, strong coupling, strong disturbance, and time delay, it is difficult to solve the overshoot and concussion problems in the control process, which has limited the improvement of register accuracy for gravure electronic equipment. Hence, a decoupling control strategy is essential to improve the quality of printed electronic products.

Register errors directly reflect the register accuracy, including two kinds [2, 3]: machine directional register errors and cross directional register errors. In general, cross directional register errors can be ignored because the lateral jitter of a moving web is very small. Thus, the focus of this paper is on machine directional register errors which are affected by many factors and are the emphasis and difficulty of multilayer register control system. In previous works, the synthesis control methods based on the PID control are the most common control strategy for the multilayer register system in the gravure printing machines. Yoshida et al. [4] established a mathematical model and proposed a cooperative register control method using feedforward and PD control for gravure printing presses. Based on the model established in [4], a speed variation compensation PD control was presented to eliminate the nondeterministic disturbance of the tension variation in speed-up process in [5]. Li et al. [6] established the mathematical model of two-layer register error and designed a control methodology based on feedforward and PID control to eliminate the interference caused by the speed and tension of upstream web. In [7], the mathematical model of register errors was established and a feedforward PID controller was proposed to cancel out the upstream speed disturbance and achieved good control effect. Chen et al. [8] developed an optimized feedforward decoupling PD register control method with membrane algorithm to generate optimized control signal 

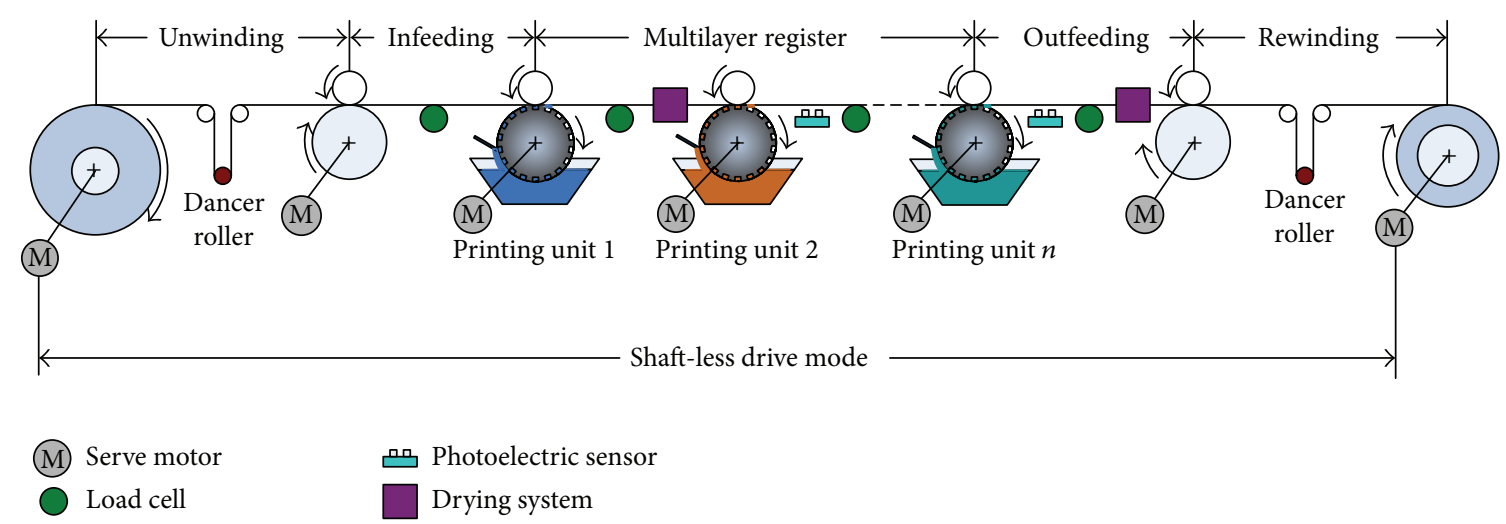

Photoelectric sensor

Drying system

FIGURE 1: Schematic diagram of a gravure printed electronic equipment.

without the loss of accuracy of print registration. In [9], Lee et al. proposed a register strategy based on PID to investigate the dominant factor affecting register error and minimize it.

Some new control methods have been applied to register control system in the recent years. A nonlinear control law is designed with the Lyapunov stability theorem such that the register errors converge to zero in [10], and the method was confirmed to have better performance than the method proposed in [4]. A decentralized memoryless state feedback control law is proposed in [11] where the input delays are converted into state delays using dynamic feedback. In [12], a control strategy based on sliding mode variable structure was proposed for multilayer register system. According to the model established in [4], Chen et al. [13] proposed a decoupling and disturbance rejection control strategy which combines extended state observer with feedforward control for register system. Kim et al. designed register control strategy considering time difference between measurement and actuation for roll-to-roll gravure-offset printing equipment in [14] and then, they [15] proposed a register control method based on a statistical approach and signal processing technology. Although most of these methods resulted in acceptable control performance for traditional printing products, such as newspapers, magazines, and leaflets, printed electronic products require much higher register accuracy. Therefore, to obtain better print quality, it is necessary to present a decoupling control strategy that could effectively deal with the strong coupling, strong interference, time delay, and uncertain nature of multilayer register system. The synthesis control strategy based on active disturbance rejection control $(\mathrm{ADRC})$ is an ideal candidate for multilayer register system. Because the essence of ADRC is that both the internal unmodeled coupling dynamics and the external disturbances can be estimated and compensated in real time [16-18], ADRC has been successfully applied in many fields [19-23]. Although initial evaluations of the application of ADRC for the regulation of register errors were performed in $[3,24]$, design difficulty of the proposed methods increases rapidly with the increase of printing layers in register system.

The objective of this research is to design a decoupling control strategy based on feedforward control and ADRC for the multilayer register system of gravure printed electronic equipment. First, a nonlinear mathematical model of the four-layer register system is constructed and a linear model of the nonlinear model is derived in detail based on perturbation method. Next, according to the linear model, a decoupling control strategy is designed based on feedforward control and ADRC for the multilayer register system. Last, to test the effectiveness of the proposed decoupling strategy, simulations and analysis compared with PID and proposed controllers are carried out.

\section{Mathematical Model}

2.1. Multilayer Register System. The schematic diagram of a $\mathrm{R} 2 \mathrm{R}$ gravure printed electronic equipment is shown in Figure 1, which is composed of an unwinding unit, an infeeding unit, a multilayer register system, an outfeeding unit, and a rewinding unit, and $n$ stands for the total number of printing units. Shaftless drive mode has been used in the equipment; that is, all of the driving shafts are driven by independent servomotors. Control of the equipment is basically composed of tension control which is applied to the unwinding, infeeding, outfeeding, and rewinding units and register control which is applied to the multilayer register system. The printing cylinder of printing unit 1 maintains a constant angular velocity, and the angular velocity of other printing cylinders is adjusted according to register errors measured by photoelectric sensors. Load cells are installed at idle rollers in the middle of continuous process for tension pickup. Two passive dancer rollers are used to reduce tension fluctuations and measure the tension signals simultaneously in the unwinding and rewinding units.

Figure 2(a) shows the gravure schematic, and Figure 2(b) shows the schematic diagram of four-layer register system which can meet the needs of many printed electronic products, such as thin film transistors (as shown in Figure 2(b)), solar cells, and RFID tags. Register is the process of aligning successive printed patterns to form a complex multilayer image. Register control is critical because if the successively printed layers are not properly aligned then the functional capabilities of the printed electronic devices are reduced or lost. However, as shown in Figure 2(b), the multilayer register system has a cumulative effect in the process of 


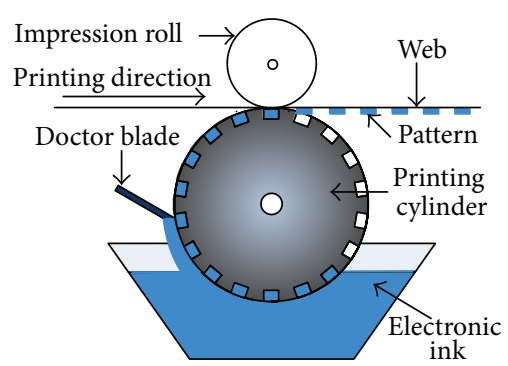

(a) Gravure schematic

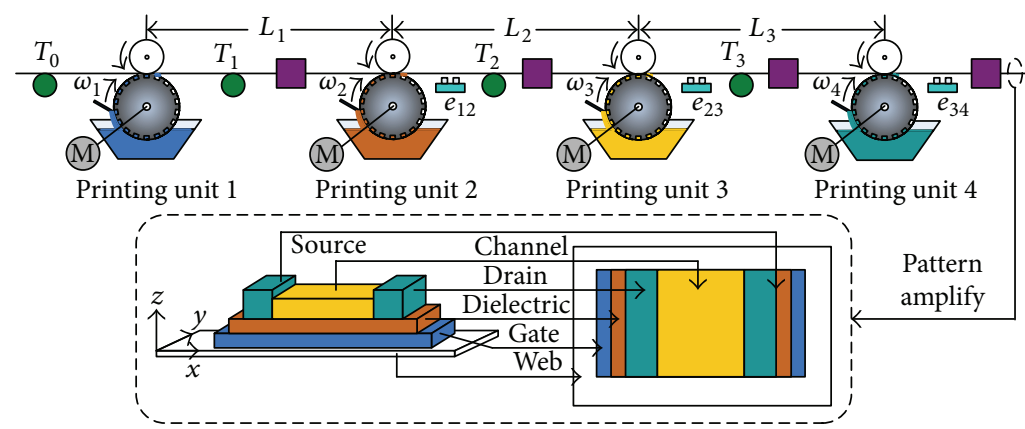

(b) Schematic diagram of a four-layer register system

FIGURE 2: Schematic diagram of the gravure and four-layer register system.

printing; namely, the adjustment of register error in upstream printing section will affect all register errors in downstream printing sections, which makes the register system a significant nonlinear, strong coupling, and time-delay system. Furthermore, the drying systems bring a large number of unknown disturbances to the register control system. Hence, to achieve good microscale register accuracy, it is a key technology that a decoupling control strategy is designed to solve the nonlinear, strong coupling, strong interference, and uncertain problems of the register system.

2.2. Register System Model. The machine directional register error of a moving web is defined in two adjacent printing cylinders as the relative difference of the distance between the previous pattern printed by the upstream printing cylinder and the later printed one in the downstream printing cylinder. According to [25], we can get the nonlinear system model of the register error between $i$ th and $(i+1)$ th printing units as follows:

$$
\begin{aligned}
A E \frac{d e_{i(i+1)}(t)}{d t}= & A E\left(R_{i+1} \omega_{i+1}(t)-R_{i} \omega_{i}\left(t-t_{T i}\right)\right) \\
& -T_{i}(t) R_{i} \omega_{i}(t) \\
& +T_{i-1}\left(t-t_{T i}\right) R_{i} \omega_{i}\left(t-t_{T i}\right),
\end{aligned}
$$

where $t_{T i}$ is transmission time (also known as time delay) and is defined by

$$
t_{T i}=\frac{L_{i}}{R_{i} \omega_{i}} \approx \frac{L_{i}}{R_{i} \omega^{*}}
$$

It is assumed that the nominal span lengths within adjacent printing units are typically same and there are no manufacturing errors in the register system. Thus, we can obtain (3) for the $n$-layer register system as follows:

$$
\begin{aligned}
& R_{1}=R_{2}=\cdots=R_{i}=\cdots=R_{n}=R \\
& L_{1}=L_{2}=\cdots=L_{i}=\cdots=L_{n}=L \\
& t_{T 1}=t_{T 2}=\cdots=t_{T i}=\cdots=t_{T n}=t_{T} .
\end{aligned}
$$

Combining (1) and (3), (1) can be represented as follows:

$$
\begin{aligned}
\frac{d e_{i(i+1)}(t)}{d t}= & R \omega_{i+1}(t)-\frac{R}{A E} T_{i}(t) \omega_{i}(t)-R \omega_{i}\left(t-t_{T}\right) \\
& +\frac{R}{A E} T_{i-1}\left(t-t_{T}\right) \omega_{i}\left(t-t_{T}\right)
\end{aligned}
$$

According to (4), Figure 2(b), and the working principle of multilayer register in gravure printing, the four-layer register system model can be expressed as follows:

$$
\begin{aligned}
\frac{d e_{12}(t)}{d t}= & R \omega_{2}(t)-\frac{R}{A E} T_{1}(t) \omega_{1}(t)-R \omega_{1}\left(t-t_{T}\right) \\
& +\frac{R}{A E} T_{0}\left(t-t_{T}\right) \omega_{1}\left(t-t_{T}\right) \\
\frac{d e_{23}(t)}{d t}= & R \omega_{3}(t)-\frac{R}{A E} T_{2}(t) \omega_{2}(t)-R \omega_{2}\left(t-t_{T}\right) \\
& +\frac{R}{A E} T_{1}\left(t-t_{T}\right) \omega_{2}\left(t-t_{T}\right) \\
\frac{d e_{34}(t)}{d t}= & R \omega_{4}(t)-\frac{R}{A E} T_{3}(t) \omega_{3}(t)-R \omega_{3}\left(t-t_{T}\right) \\
& +\frac{R}{A E} T_{2}\left(t-t_{T}\right) \omega_{3}\left(t-t_{T}\right),
\end{aligned}
$$

where $\omega_{2}(t), \omega_{3}(t)$, and $\omega_{4}(t)$ are the input signals of the register system and $e_{12}(t), e_{23}(t)$, and $e_{34}(t)$ are the output signals of the register system.

Equation (5) shows that the four-layer register system is a multi-input multioutput, strong coupling, time-delay, and nonlinear system. The nonlinear model can be linearized using the perturbation method for the controller design. According to the perturbation method, all the variables in (5) are expressed using the steady-state values and the variable values, as described by the following equation:

$$
\begin{gathered}
e_{i(i+1)}(t)=e^{*}+\Delta e_{i(i+1)}(t) \\
\omega_{i}(t)=\omega^{*}+\Delta \omega_{i}(t) \\
T_{i}(t)=T^{*}+\Delta T_{i}(t) .
\end{gathered}
$$


Substituting (6) into (5) and ignoring high order small quantity, (5) can be rewritten as follows:

$$
\begin{aligned}
\frac{d \Delta e_{12}(t)}{d t}= & R \Delta \omega_{2}(t)-\frac{R T^{*}}{A E} \Delta \omega_{1}(t) \\
& +R\left(\frac{T^{*}}{A E}-1\right) \Delta \omega_{1}\left(t-t_{T}\right) \\
& +\frac{R \omega^{*}}{A E}\left[\Delta T_{0}\left(t-t_{T}\right)-\Delta T_{1}(t)\right] \\
\frac{d \Delta e_{23}(t)}{d t}= & R \Delta \omega_{3}(t)-\frac{R T^{*}}{A E} \Delta \omega_{2}(t) \\
& +R\left(\frac{T^{*}}{A E}-1\right) \Delta \omega_{2}\left(t-t_{T}\right) \\
& +\frac{R \omega^{*}}{A E}\left[\Delta T_{1}\left(t-t_{T}\right)-\Delta T_{2}(t)\right] \\
\frac{d \Delta e_{34}(t)}{d t}= & R \Delta \omega_{4}(t)-\frac{R T^{*}}{A E} \Delta \omega_{3}(t) \\
& +R\left(\frac{T^{*}}{A E}-1\right) \Delta \omega_{3}\left(t-t_{T}\right) \\
& +\frac{R \omega^{*}}{A E}\left[\Delta T_{2}\left(t-t_{T}\right)-\Delta T_{3}(t)\right] .
\end{aligned}
$$

Considering $T^{*} \ll A E$ and omitting the notation " $\Delta$ " to improve the readability, we can obtain the linearized model of the four-layer register system as follows:

$$
\begin{aligned}
\frac{d e_{12}(t)}{d t}= & R \omega_{2}(t)-\frac{R T^{*}}{A E} \omega_{1}(t)-R \omega_{1}\left(t-t_{T}\right) \\
& +\frac{R \omega^{*}}{A E}\left[T_{0}\left(t-t_{T}\right)-T_{1}(t)\right] \\
\frac{d e_{23}(t)}{d t}= & R \omega_{3}(t)-\frac{R T^{*}}{A E} \omega_{2}(t)+R \omega_{2}\left(t-t_{T}\right) \\
& +\frac{R \omega^{*}}{A E}\left[T_{1}\left(t-t_{T}\right)-T_{2}(t)\right] \\
\frac{d e_{34}(t)}{d t}= & R \omega_{4}(t)-\frac{R T^{*}}{A E} \omega_{3}(t)+R \omega_{3}\left(t-t_{T}\right) \\
& +\frac{R \omega^{*}}{A E}\left[T_{2}\left(t-t_{T}\right)-T_{3}(t)\right] .
\end{aligned}
$$

With Laplace transform, the transfer functions of the four-layer register system can be got:

$$
\begin{aligned}
E_{12}(s)= & G_{A}(s) W_{2}(s)+G_{B}(s) W_{1}(s)+G_{C}(s) T_{0}(s) \\
& +G_{D}(s) T_{1}(s) \\
E_{23}(s)= & G_{A}(s) W_{3}(s)+G_{B}(s) W_{2}(s)+G_{C}(s) T_{1}(s) \\
& +G_{D}(s) T_{2}(s) \\
E_{34}(s)= & G_{A}(s) W_{4}(s)+G_{B}(s) W_{3}(s)+G_{C}(s) T_{2}(s) \\
& +G_{D}(s) T_{3}(s),
\end{aligned}
$$

where $G_{A}(s), G_{B}(s), G_{C}(s)$, and $G_{D}(s)$ are expressed as

$$
\begin{aligned}
& G_{A}(s)=\frac{R}{s} \\
& G_{B}(s)=-\frac{R}{s}\left(\frac{T^{*}}{A E}+e^{-t_{T} s}\right) \\
& G_{C}(s)=\frac{R \omega^{*}}{A E s} e^{-t_{T} s} \\
& G_{D}(s)=-\frac{R \omega^{*}}{A E s} .
\end{aligned}
$$

According to (9), we can obtain the linear model of the adjacent two-layer register error between $i$ th and $(i+1)$ th printing unit as follows:

$$
\begin{aligned}
E_{i(i+1)}(s)= & G_{A}(s) W_{i+1}(s)+G_{B}(s) W_{i}(s) \\
& +G_{C}(s) T_{i-1}(s)+G_{D}(s) T_{i}(s) .
\end{aligned}
$$

As shown in (11), the register error $E_{i(i+1)}(s)$ is the combined result of multiple factors including $W_{i}(s), W_{i+1}(s)$, $T_{i-1}(s)$, and $T_{i}(s)$. In shaftless drive mode, $W_{i+1}(s)$ is the control variable of two-layer register system whose corresponding transfer function $G_{A}(s)$ is the characteristics of register system on which the controller design is based. $W_{i}(s)$ is the coupling interference of the angular velocity from upstream printing unit $i . T_{i-1}(s)$ and $T_{i}(s)$ are the coupling interference of the web tension.

\section{Design Decoupling Control Strategy}

According to (11), an integrated decoupling control strategy based on feedforward control and ADRC is proposed for twolayer register system in Figure 3.

Figure 3 shows that the decoupling control strategy consists of a feedforward controller composed of $C_{W i}(s), C_{T i-1}(s)$, and $C_{T i}(s)$ and an ADRC controller. $C_{W i}(s), C_{T i-1}(s)$, and $C_{T i}(s)$ compensate the register errors caused by the variations of $W_{i}, T_{i-1}$, and $T_{i}$, respectively. The ADRC controller adjusts inputs $e_{r i(i+1)}$ of the register system and actively estimates and compensates the unmodeled coupling dynamics and disturbances in real time.

3.1. Design Feedforward Controller. As shown in Figure 2, the angular velocity of printing cylinders and the tension of the web can be measured directly by encoders installed at servomotors and load cells, respectively. Therefore, additive feedforward controller can alleviate the register errors caused by upstream modeled interferences through preadjustment. 


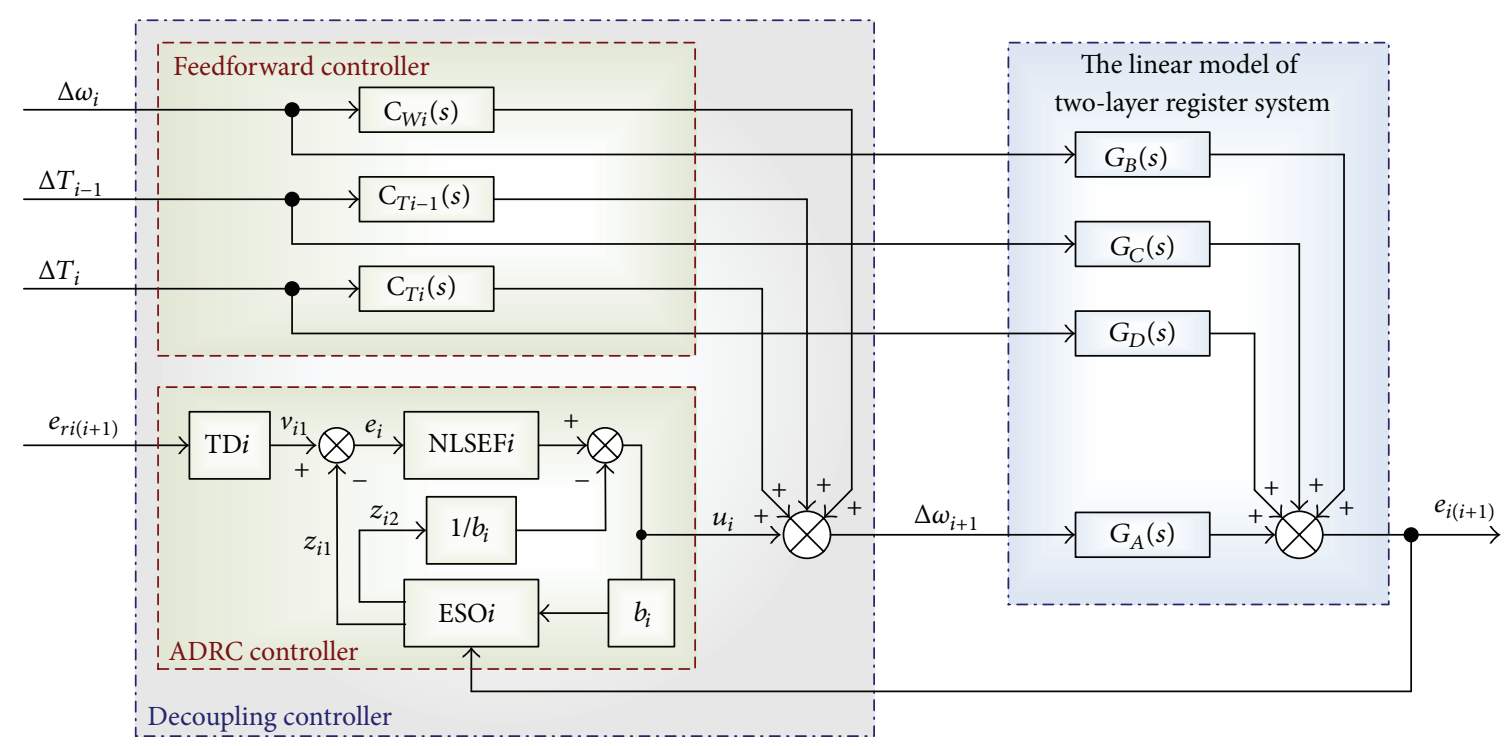

FIGURE 3: Block diagram of the integrated decoupling control strategy.

According to Figure 3 and the superposition theorem of linear system, the output of the two-layer register system can be written as

$$
\begin{aligned}
E_{i(i+1)}(s)= & \frac{G_{A}(s) C_{i}(s)}{1+G_{A}(s) C_{i}(s)} E_{r i(i+1)}(s) \\
& +\frac{G_{B}(s)+C_{W i}(s) G_{A}(s)}{1+G_{A}(s) C_{i}(s)} W_{i}(s) \\
& +\frac{G_{C}(s)+C_{T i-1}(s) G_{A}(s)}{1+G_{A}(s) C_{i}(s)} T_{i-1}(s) \\
& +\frac{G_{D}(s)+C_{T i}(s) G_{A}(s)}{1+G_{A}(s) C_{i}(s)} T_{i}(s) .
\end{aligned}
$$

The feedforward controller can be designed based on invariance principle for canceling out the register errors caused by the variations of $W_{i}, T_{i-1}$, and $T_{i}$. We can obtain (13) as follows:

$$
\begin{aligned}
G_{B}(s)+C_{W i}(s) G_{A}(s) & =0 \\
G_{C}(s)+C_{T i-1}(s) G_{A}(s) & =0 \\
G_{D}(s)+C_{T i}(s) G_{A}(s) & =0 .
\end{aligned}
$$

Hence, the feedforward controller (namely, $C_{W i}(s)$, $C_{T i-1}(s)$, and $\left.C_{T i}(s)\right)$ can be designed as follows:

$$
\begin{gathered}
C_{W i}(s)=-\frac{G_{B}(s)}{G_{A}(s)}=\frac{T^{*}}{A E}+e^{-t_{T} s} \\
C_{T i-1}(s)=-\frac{G_{C}(s)}{G_{A}(s)}=-\frac{\omega^{*}}{A E} e^{-t_{T} s} \\
C_{T i}(s)=-\frac{G_{D}(s)}{G_{A}(s)}=\frac{\omega^{*}}{A E} .
\end{gathered}
$$

3.2. Design ADRC Controller. Because (11) shows that the two-layer register system is the first-order system, one firstorder ADRC controller is needed for the decoupling control strategy. As shown in Figure 3, the ADRC controller consists of a tracking differentiator (TD), an extended state observer (ESO), and a nonlinear states error feedback (NLSEF).

The TD is a nonlinear component in which a tracking signal and an approximately differential signal of the system input can be acquired according to the system input signal, even for a nondifferentiable or noncontinuous input signal. Figure 3 shows that $v_{i 1}$ is tracking the signal of reference input $e_{r i(i+1)}$. According to [17-19], the discrete forms of the TD $i$ are expressed as follows:

$$
\begin{aligned}
f h_{i}(n) & =\text { fhan }\left(v_{i 1}(n)-e_{r i(i+1)}(n), v_{i 2}(n), r_{i}, h\right) \\
v_{i 1}(n+1) & =v_{i 1}(n)+h v_{i 2}(n) \\
v_{i 2}(n+1) & =v_{i 2}(n)+h f h_{i}(n),
\end{aligned}
$$

where $n$ is the natural number $(n=0,1,2,3, \ldots), r_{i}$ is the velocity factor, and $h$ is the sampling step. According to $[18,21,26]$, fhan $\left(x_{1}, x_{2}, r, h\right)$ is a nonlinear function that guarantees the fastest convergence from $v_{i 1}$ to $e_{r i(i+1)}$ without any overshoot and is defined as follows:

$$
\begin{aligned}
& d=r h ; \\
& d_{0}=h d \\
& y=x_{1}+h x_{2} ; \\
& a_{0}=\left(d^{2}+8 r|y|\right)^{1 / 2}
\end{aligned}
$$




$$
\begin{gathered}
a= \begin{cases}x_{2}+\frac{a_{0}-d}{2} \operatorname{sign}(y), & |y|>d_{0} \\
x_{2}+\frac{y}{h}, & |y| \leq d_{0}\end{cases} \\
\text { fhan }\left(x_{1}, x_{2}, r, h\right)=- \begin{cases}r \operatorname{sign}(a), & |a|>d \\
r \frac{a}{d}, & |a| \leq d .\end{cases}
\end{gathered}
$$

The ESO is the core of ADRC which can not only track the system output variables and their differentiated signals but also actively estimate unmodeled coupling dynamics and disturbances in real time. Figure 3 shows that $z_{i 1}$ and $z_{i 2}$ track output $e_{i(i+1)}$ and estimated value of the unmodeled coupling dynamics and disturbances in the register system, respectively. According to $[17,18]$, the discrete forms of the second-order ESO $i$ are obtained as follows:

$$
\begin{aligned}
q_{i}(n) & =z_{i 1}(n)-e_{i(i+1)}(n) \\
z_{i 1}(n+1) & =z_{i 1}(n)+h\left(z_{i 2}(n)-\beta_{i 1} q_{i}(n)+b_{i} u_{i}(n)\right) \\
z_{i 2}(n+1) & =z_{i 2}(n)+h\left(-\beta_{i 2} \mathrm{fal}\left(q_{i}(n), 0.5, h\right)\right),
\end{aligned}
$$

where $\beta_{i 1}$ and $\beta_{i 2}$ are the ESO gains and $b_{i}$ is the compensation factor. The $\mathrm{fal}(e, \alpha, \delta)$ is a nonlinear function defined as follows:

$$
\operatorname{fal}(e, \alpha, \delta)= \begin{cases}\frac{e}{\delta^{1-\alpha}}, & |e| \leq \delta \\ |e|^{\alpha} \operatorname{sign}(e), & |e|>\delta\end{cases}
$$

The NLSEF is a nonlinear combination of the resulting difference $e_{i}$ caused by the $v_{i 1}$ and $z_{i 1}$ generated by TD and ESO, respectively. The control law of the ADRC can actively compensate for the unmodeled coupling dynamics and disturbances which are estimated by ESO in real time. According to $[17,18]$, we can obtain the discrete forms of the NLSEF $i$ as follows:

$$
\begin{aligned}
& e_{i}(n+1)=v_{i 1}(n+1)-z_{i 1}(n+1) \\
& u_{i}(n+1)=k_{p i} \mathrm{fal}\left(e_{i}(n+1), 0.5, \delta\right)-\frac{z_{i 2}(n+1)}{b_{i}},
\end{aligned}
$$

where $\delta$ is the interval length of the linear segment and $k_{p i}$ is the proportionality coefficient.

Combining (15), (17), and (19), the discrete algorithm of the ADRC $i$ is expressed as

$$
\begin{aligned}
f h_{i}(n) & =\text { fhan }\left(v_{i 1}(n)-e_{r i(i+1)}(n), v_{i 2}(n), r_{i}, h\right) \\
v_{i 1}(n+1) & =v_{i 1}(n)+h v_{i 2}(n) \\
v_{i 2}(n+1) & =v_{i 2}(n)+h f h_{i}(n)
\end{aligned}
$$

$$
\begin{aligned}
q_{i}(n) & =z_{i 1}(n)-e_{i(i+1)}(n) \\
z_{i 1}(n+1) & =z_{i 1}(n)+h\left(z_{i 2}(n)-\beta_{i 1} q_{i}(n)+b_{i} u_{i}(n)\right) \\
z_{i 2}(n+1) & =z_{i 2}(n)+h\left(-\beta_{i 2} \mathrm{fal}\left(q_{i}(n), 0.5, h\right)\right) \\
e_{i}(n+1) & =v_{i 1}(n+1)-z_{i 1}(n+1) \\
u_{i}(n+1) & =k_{p i} \mathrm{fal}\left(e_{i}(n+1), 0.5, \delta\right)-\frac{z_{i 2}(n+1)}{b_{i}}
\end{aligned}
$$

In actual printing process, the reference input of the register system is zero, scilicet $e_{r i(i+1)}=0$. Consequently, the discrete algorithm of the ADRC can also be represented as follows:

$$
\begin{aligned}
q_{i}(n) & =z_{i 1}(n)-e_{i(i+1)}(n) \\
z_{i 1}(n+1) & =z_{i 1}(n)+h\left(z_{i 2}(n)-\beta_{i 1} q_{i}(n)+b_{i} u_{i}(n)\right) \\
z_{i 2}(n+1) & =z_{i 2}(n)+h\left(-\beta_{i 2} \mathrm{fal}\left(q_{i}(n), 0.5, h\right)\right) \\
e_{i}(n+1) & =-z_{i 1}(n+1) \\
u_{i}(n+1) & =k_{p i} \mathrm{fal}\left(e_{i}(n+1), 0.5, \delta\right)-\frac{z_{i 2}(n+1)}{b_{i}} .
\end{aligned}
$$

As shown in Figure 3, output $\Delta \omega_{i+1}$ of the decoupling control strategy is composed of the ADRC controller's output $u_{i}$ and the feedforward controller's outputs.

\section{Simulation and Analysis}

The comparative simulation of the four-layer register system between proposed decoupling control strategy and PID and ADRC control strategies is performed to investigate the performance of the proposed decoupling control strategy. The structure of the decoupling control strategy for fourlayer register system is shown in Figure 4. The decoupling controller $i(i=1,2,3)$ of the two-layer register system in Figure 4 is shown in Figure 3. Figures 5(a) and 5(b) show the structures of the PID and ADRC control strategies, respectively, for four-layer register system.

The simulation adopts a fixed-step size mode and the fixed-step size is $10 \mathrm{~ms}$ (namely, the sampling step $h=10 \mathrm{~ms}$ ) in MATLAB. The parameters of the register system used in the simulation are summarized in Table 1. On the basis of the same mathematical model and parameters, all parameters of ADRC and PID controllers are adjusted under the condition of $\omega^{*}=1000 \mathrm{rad} / \mathrm{min}$, and the parameters are not changed with the change of the simulation conditions. The adjustment principle and procedure of ADRC controller parameters have been introduced in [27-29]. According to these literatures and our experiences, the adjustment procedure of the ADRC controller parameters is as follows.

Step 1. ESO parameter $\beta_{i 1}$ is equal to the reciprocal of the sampling step $h$. Thus, we can obtain $\beta_{i 1}=100$. 


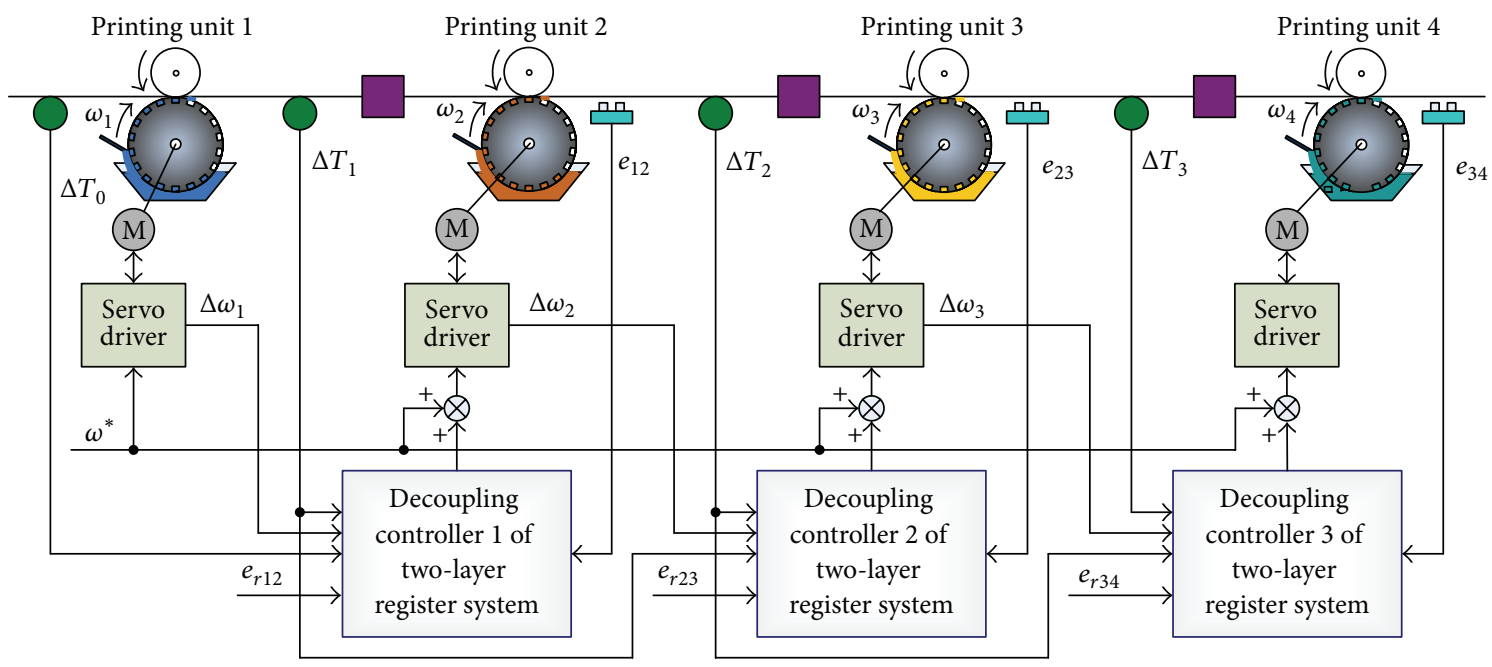

FIGURE 4: Structure of the decoupling control strategy for four-layer register system.

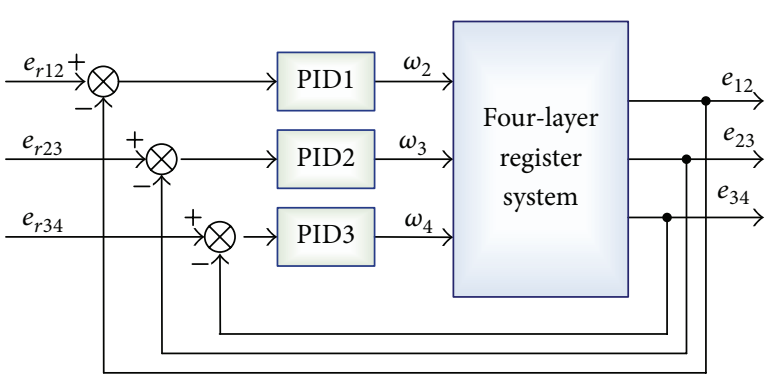

(a) Structure of the PID control strategy

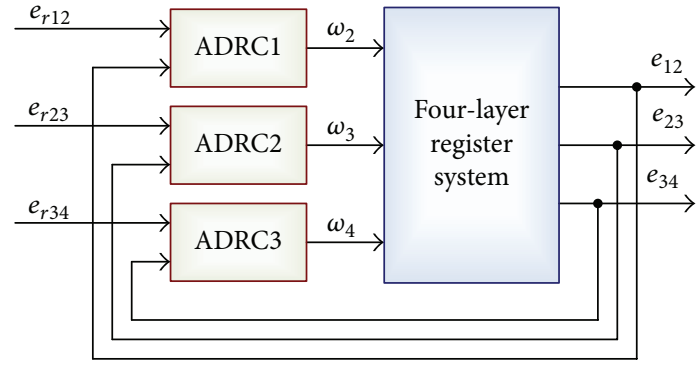

(b) Structure of the ADRC control strategy

FIGURE 5: Structures of the PID and ADRC control strategies for four-layer register system.

TABLE 1: System parameters in simulation.

\begin{tabular}{lcc}
\hline Parameters & Value & Units \\
\hline$L$ & 6.28 & $\mathrm{~m}$ \\
$R$ & 0.2 & $\mathrm{~m}$ \\
$T_{0}$ & 100 & $\mathrm{~N}$ \\
$A$ & $2 \times 10^{-5}$ & $\mathrm{~m}^{2}$ \\
$E$ & $2.1 \times 10^{9}$ & $\mathrm{~Pa}$ \\
\hline
\end{tabular}

Step 2. The ESO parameter $\beta_{i 2}$ is greater than $\beta_{i 1}$. Under the open-loop condition, $\beta_{i 2}$ is adjusted to make $z_{i 1}$ trace $e_{i(i+1)}$ with no vibration and $\beta_{i 2}$ is as big as possible under no vibration condition of the ESO output $z_{i 2}$.

Step 3. The TD parameter $r_{i}$ is adjusted to make $v_{i 1}$ and $v_{i 2}$ quickly trace system reference input $e_{r i(i+1)}$ and differentiated signal of $e_{r i(i+1)}$, respectively, in the open-loop condition.

Step 4. Under the closed-loop condition, the NLSEF parameter $k_{i p}$ is adjusted to make the output $e_{i(i+1)}$ stable within reference input $e_{r i(i+1)}$ with no vibration.

The adjusted parameters of the PID and ADRC controllers are listed in Table 2.
4.1. Performance against Tension Interference. $T_{0}(t)$ has a step change from $100 \mathrm{~N}$ to $130 \mathrm{~N}$ at $5 \mathrm{~s}$ and a step change from $130 \mathrm{~N}$ to $100 \mathrm{~N}$ at $10 \mathrm{~s}$ to investigate the performance against tension coupling interference of the proposed decoupling control strategy. The simulation behaviors of the PID, ADRC, and proposed decoupling control strategies are shown in Figures 6, 7, and 8 .

Figures 6 and 7 show that, under the tension interference of $T_{0}(t)$, the register errors in PID and ADRC control strategies increase gradually with the increase of $\omega_{1}(t)$. As shown in Figure 8, under the same interference, the register errors in the proposed control strategy present the same trend as those in the PID and ADRC control strategies. However, compared with PID and ADRC control strategies, the range and duration of the register errors under the proposed control strategy are much smaller in the same simulation conditions, as shown in Figures 6 and 7. For example, when $\omega^{*}$ is equal to $2000 \mathrm{rad} / \mathrm{min}$, the ranges of $e_{1}(t)$ fluctuation are $39.5 \mu \mathrm{m}$ and $18.32 \mu \mathrm{m}$ in the PID and ADRC control strategies, respectively, but under the proposed control strategy, the range of $e_{1}(t)$ fluctuation is only $38.6 \mathrm{~nm}$.

The simulation results indicate that the feedforward and ADRC controllers can effectively compensate the register errors caused by the variations of $T_{0}(t)$; namely, the proposed decoupling control strategy has better performance against 
TABLE 2: Controller parameters in simulation.

\begin{tabular}{|c|c|c|}
\hline Control strategy & Controller & Controller parameters \\
\hline \multirow{3}{*}{ PID } & PID1 & $k_{1 p}=70, k_{1 i}=30, k_{1 d}=1.2$ \\
\hline & PID2 & $k_{2 p}=75, k_{2 i}=32, k_{2 d}=1.3$ \\
\hline & PID3 & $k_{3 p}=80, k_{3 i}=35, k_{3 d}=1.3$ \\
\hline \multirow{3}{*}{ ADRC } & ADRC1 & $\beta_{11}=100, \beta_{12}=830, k_{1 p}=1.95, r_{1}=750$ \\
\hline & ADRC2 & $\beta_{21}=100, \beta_{22}=840, k_{2 p}=3.86, r_{1}=750$ \\
\hline & ADRC3 & $\beta_{31}=100, \beta_{32}=854, k_{3 p}=4.75, r_{1}=750$ \\
\hline \multirow{3}{*}{ Proposed decoupling control } & $\mathrm{ADRC1}$ & $\beta_{11}=100, \beta_{12}=890, k_{1 p}=1.35, r_{1}=750$ \\
\hline & ADRC2 & $\beta_{21}=100, \beta_{22}=930, k_{2 p}=3.26, r_{1}=750$ \\
\hline & ADRC3 & $\beta_{31}=100, \beta_{32}=956, k_{3 p}=4.35, r_{1}=750$ \\
\hline
\end{tabular}

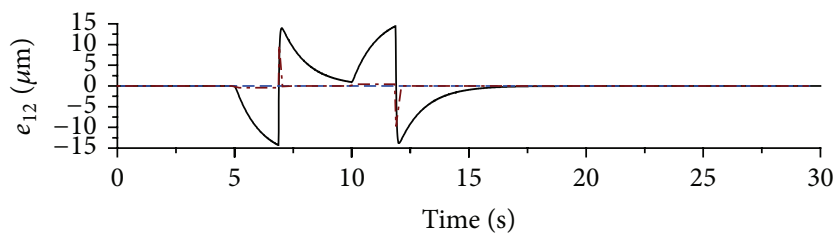

— PID -.. ADRC

(a) Register error $e_{12}$

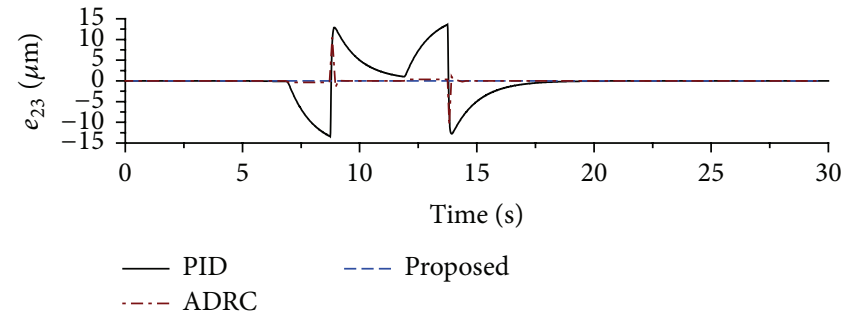

(b) Register error $e_{23}$

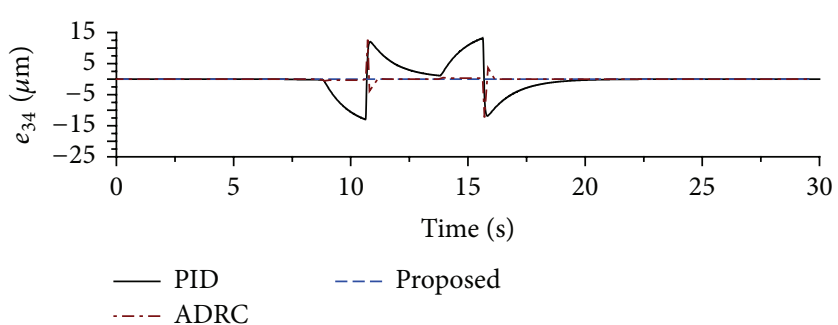

(c) Register error $e_{34}$

Figure 6: Performance against tension interference for $\omega^{*}=1000 \mathrm{rad} / \mathrm{min}$.

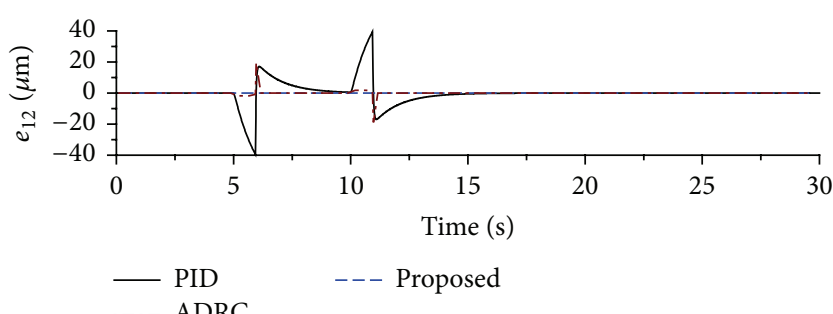

(a) Register error $e_{12}$

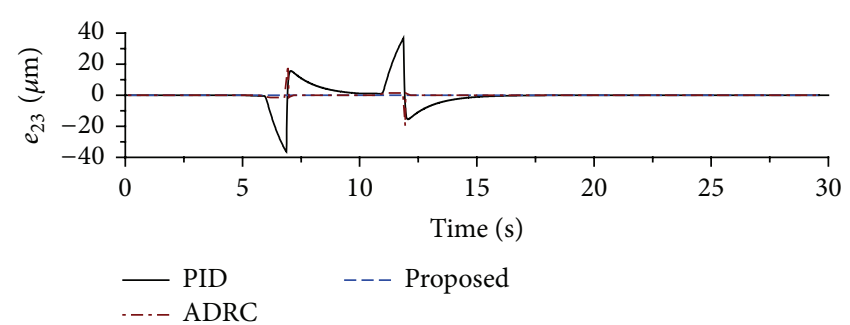

(b) Register error $e_{23}$

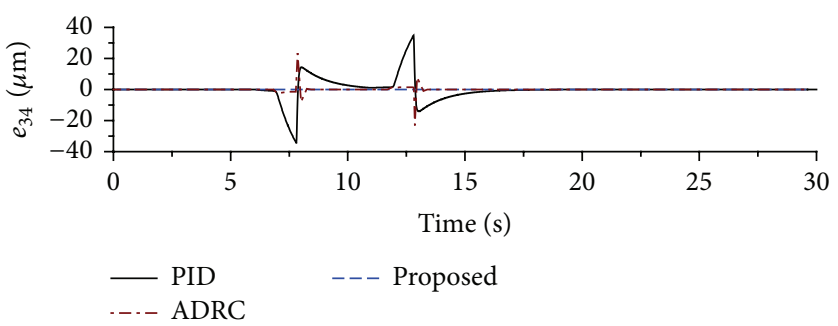

(c) Register error $e_{34}$

FIgURE 7: Performance against tension interference for $\omega^{*}=2000 \mathrm{rad} / \mathrm{min}$. 


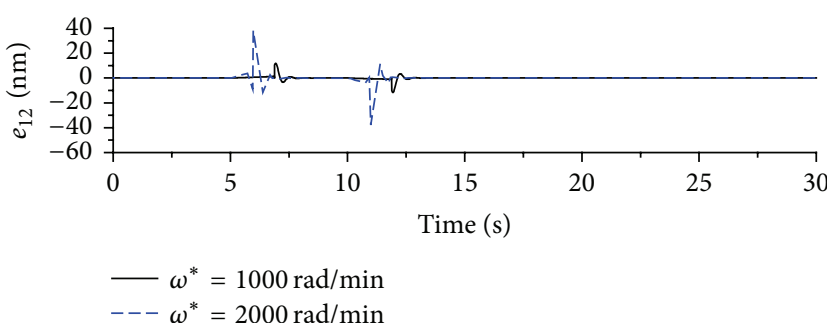

(a) Register error $e_{12}$

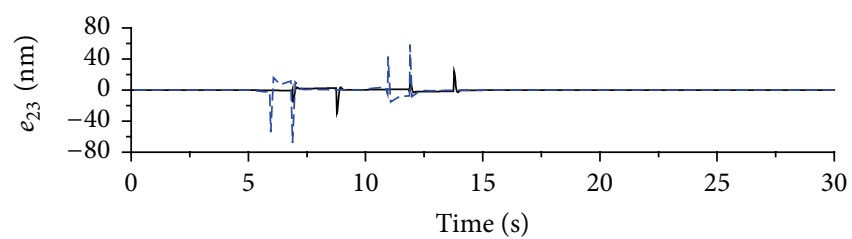

$\omega^{*}=1000 \mathrm{rad} / \mathrm{min}$

(b) Register error $e_{23}$

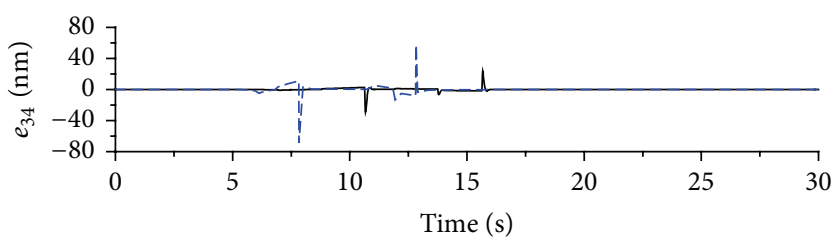

$\omega^{*}=1000 \mathrm{rad} / \mathrm{min}$

$---\omega^{*}=2000 \mathrm{rad} / \mathrm{min}$

(c) Register error $e_{34}$

FIGURE 8: Response curves of the proposed decoupling control strategy.

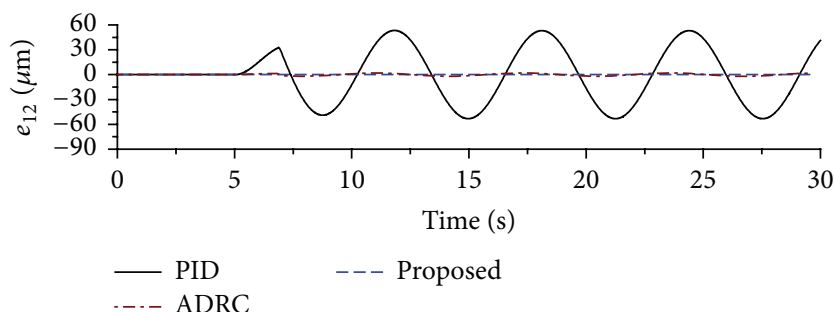

(a) Register error $e_{12}$

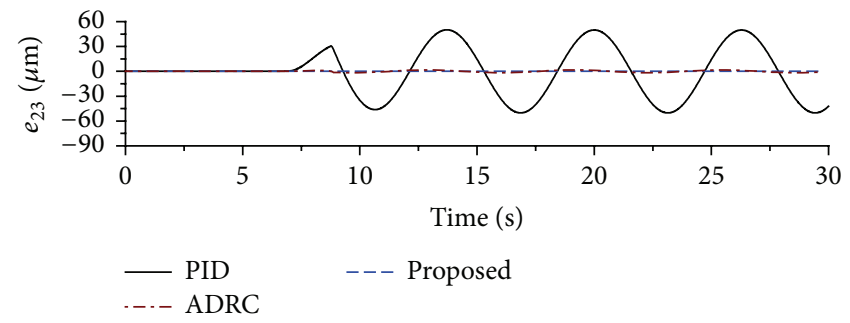

(b) Register error $e_{23}$

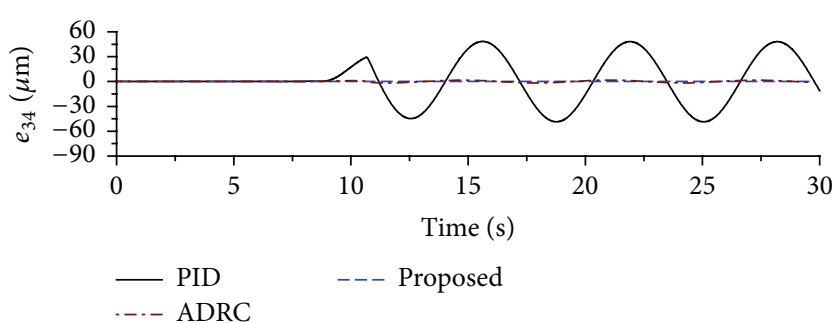

(c) Register error $e_{34}$

FIGURE 9: Performance against speed interference for $\omega^{*}=1000 \mathrm{rad} / \mathrm{min}$.

tension coupling interferences than the PID and ADRC control strategies.

4.2. Performance against Speed Interference. A sinusoidal interference of $\omega_{1}(t)$ is set at $5 \mathrm{~s}$ with amplitude $1 \mathrm{rad} / \mathrm{min}$ and frequency $1 \mathrm{rad} / \mathrm{s}$ to demonstrate the ability against speed coupling interference of the proposed decoupling control strategy. Figures 9 and 10 show the comparative performance of the PID, ADRC, and proposed decoupling control strategies. Figures 11 and 12 illustrate the behaviors of the ADRC and proposed decoupling control strategies, respectively.

Figures 9-12 illustrate that the fluctuation of register errors caused by speed interference of $\omega_{1}(t)$ has the same frequency with the interference in the PID, ADRC, and proposed control strategies. Unfortunately, the range of register errors under the PID control strategy is much greater than that under the ADRC and proposed control strategies in the same simulation condition, as shown in Figures 9 and 10. Compared with ADRC control strategy, the range of the register errors under the proposed control strategy is much smaller in the same simulation conditions, as shown in Figures 11 and 12. For instance, when $\omega^{*}$ is equal to $1000 \mathrm{rad} / \mathrm{min}$, the amplitude of $e_{1}(t)$ is only $8.3 \mathrm{~nm}$ in the proposed control strategy, but it is $53.2 \mu \mathrm{m}$ in the PID control strategy and $1.96 \mu \mathrm{m}$ in the ADRC control strategy.

The simulation results show that because the feedforward and ADRC controllers can obviously alleviate the register errors caused by the interference of $\omega_{1}(t)$, the proposed 


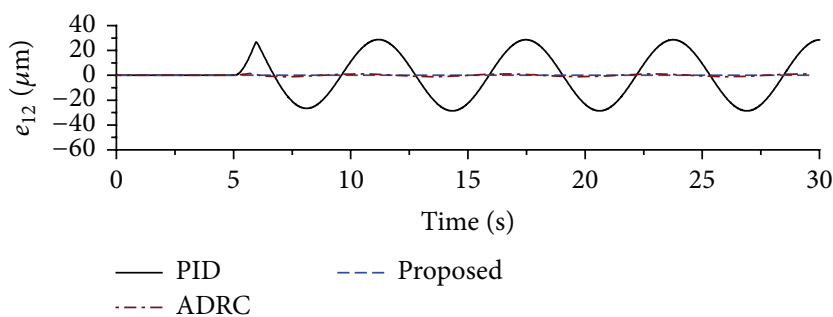

(a) Register error $e_{12}$

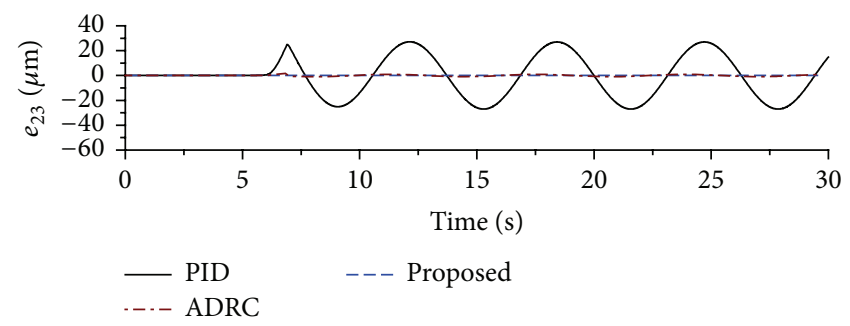

(b) Register error $e_{23}$

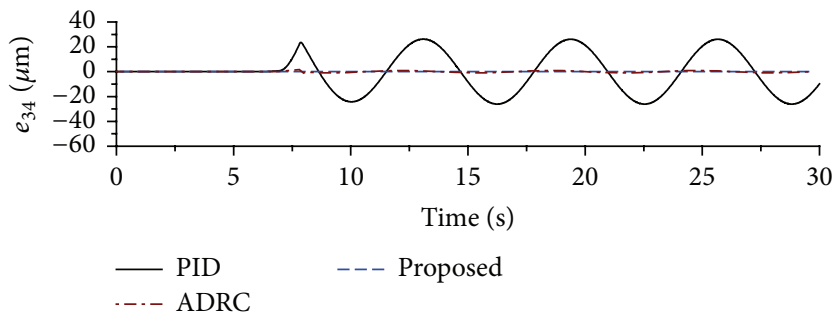

(c) Register error $e_{34}$

FIgURE 10: Performance against speed interference for $\omega^{*}=2000 \mathrm{rad} / \mathrm{min}$.

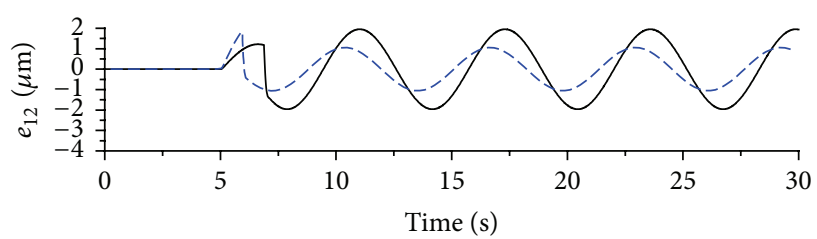

$\begin{aligned}-\omega^{*} & =1000 \mathrm{rad} / \mathrm{min} \\ --\omega^{*} & =2000 \mathrm{rad} / \mathrm{min}\end{aligned}$

(a) Register error $e_{12}$

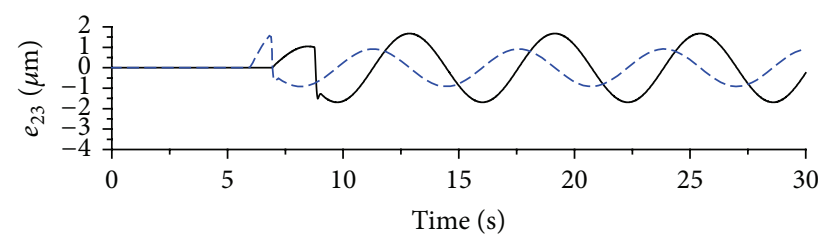

$\begin{aligned}-\omega^{*} & =1000 \mathrm{rad} / \mathrm{min} \\ --\omega^{*} & =2000 \mathrm{rad} / \mathrm{min}\end{aligned}$

(b) Register error $e_{23}$

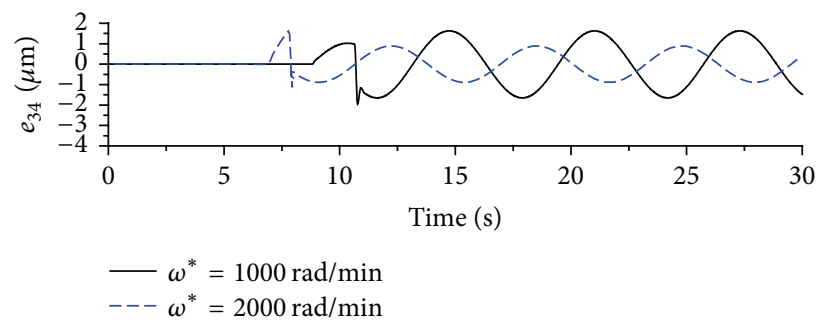

(c) Register error $e_{34}$

FIgURE 11: Response curves of the ADRC control strategy.

decoupling control strategy has better ability against speed coupling interferences than the PID and ADRC control strategies.

4.3. Performance against Web Characteristic Change. The elastic modulus of the web material decreases to $80 \%$ in order to establish the performance against characteristic change of web for the proposed decoupling control strategy. With the step change of $T_{0}(t)$ from $100 \mathrm{~N}$ to $130 \mathrm{~N}$ at $5 \mathrm{~s}$ and from $130 \mathrm{~N}$ to $100 \mathrm{~N}$ at $10 \mathrm{~s}$, Figures 13, 14, and 15 illustrate the simulation performance of the PID, ADRC, and proposed decoupling control strategies, respectively, when $\omega^{*}$ is equal to $2000 \mathrm{rad} / \mathrm{min}$.

Figures 13 and 14 indicate that, under the PID and ADRC control strategies, the register errors increase gradually with a decrease in $E$. For example, the range of $e_{1}(t)$ fluctuation increases from $39.3 \mu \mathrm{m}$ to $50.1 \mu \mathrm{m}$ in the PID control strategy and from $18.32 \mu \mathrm{m}$ to $22.31 \mu \mathrm{m}$ in the ADRC control strategy. Figure 15 shows that, with a decrease in $E$, the register errors also increase gradually in the proposed decoupling control strategy. For instance, the range of $e_{1}(t)$ is $38.6 \mathrm{~nm}$ to $46.2 \mathrm{~nm}$ when $E=2.1 \times 10^{9} \mathrm{~Pa}$ and $E=1.68 \times 10^{9} \mathrm{~Pa}$, respectively. However, with the same simulation condition, the increasing ranges of the PID and ADRC control strategies are $27.5 \%$ and $21.8 \%$, respectively, which are greater than the increasing range $19.7 \%$ of register errors under the proposed control strategy.

The simulation results illustrate that because the ADRC controllers can actively estimate and compensate the register errors caused by characteristic change of web, the ADRC and 


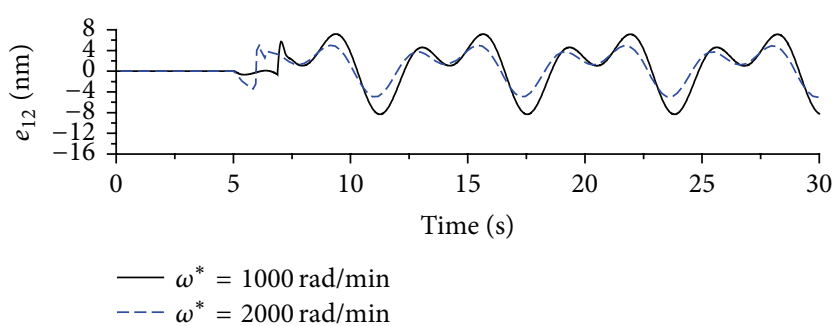

(a) Register error $e_{12}$

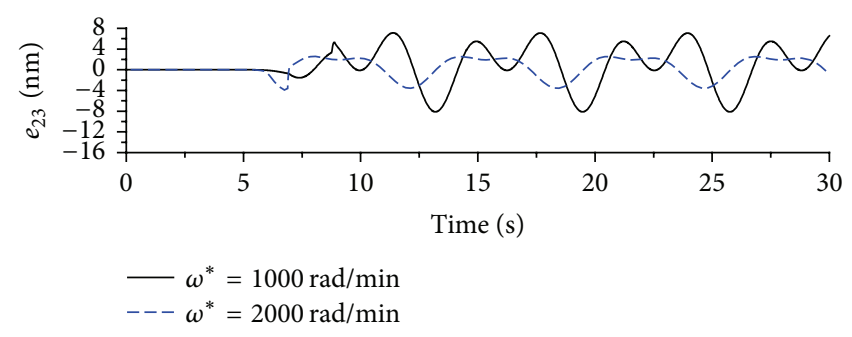

(b) Register error $e_{23}$

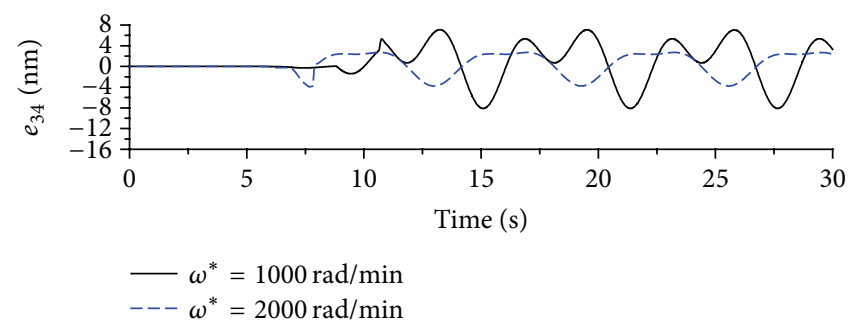

(c) Register error $e_{34}$

FIGURE 12: Response curves of the proposed decoupling control strategy.

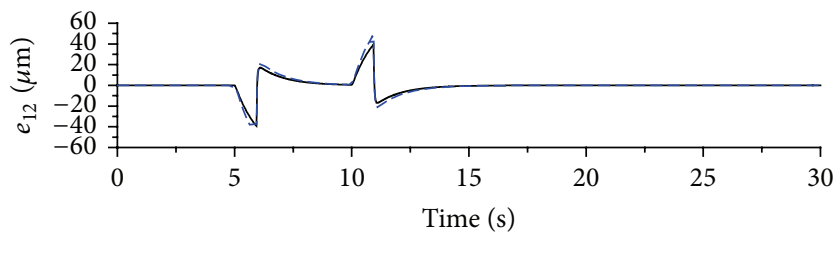

$-E$
$---E * 80 \%$

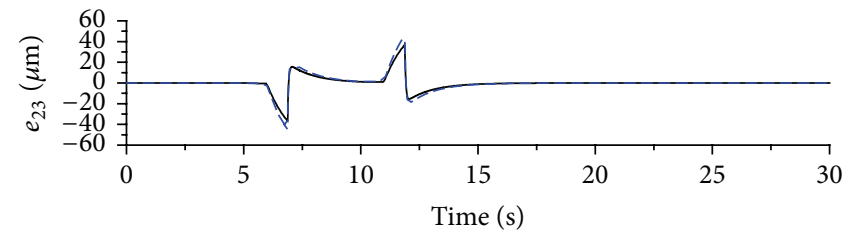

$-E$
$--E * 80 \%$

(b) Register error $e_{23}$

(a) Register error $e_{12}$

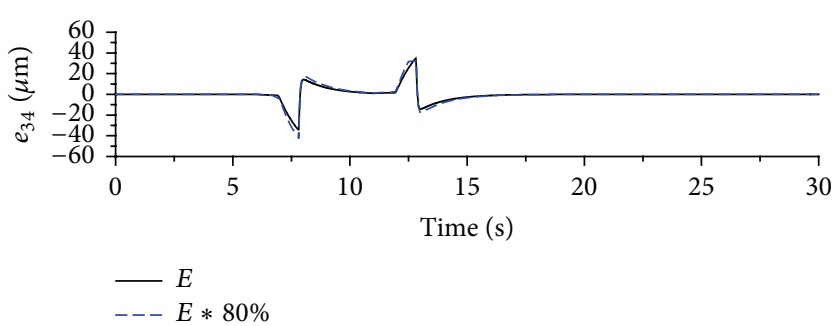

(c) Register error $e_{34}$

FIGURE 13: Response curves of the PID control strategy.

proposed control strategies have better capability against web characteristic changes than the PID control strategy.

\section{Conclusions}

In gravure printed electronic equipment, register accuracy is the most important index for the quality of multilayer register system. Therefore, in order to improve the register accuracy of multilayer register system, this paper proposes an innovative decoupling control synthesis strategy based on feedforward control and ADRC for the design of a register decoupling controller for the multilayer register system. The strategy is unique in which it uses feedforward controllers to compensate the register errors caused by the modeled interferences and uses ADRC controllers to adjust the inputs of the register system and actively estimate and compensate the register errors caused by the unmodeled disturbances in real time, which makes the accuracy of the register controller greatly improve.

The simulation results illustrate that the proposed decoupling control strategy not only can effectively compensate the register errors caused by the variations of $T_{0}(t)$ and $\omega_{1}(t)$ (namely, modeled interferences) but also can obviously alleviate the register errors caused by the change of $E$ (namely, unmodeled disturbance). The stability of the ADRC controller for nonlinear system has been proved in [30-32]. In this paper, although the stability of the proposed decoupling control strategy is not strictly proved by stability criterion 


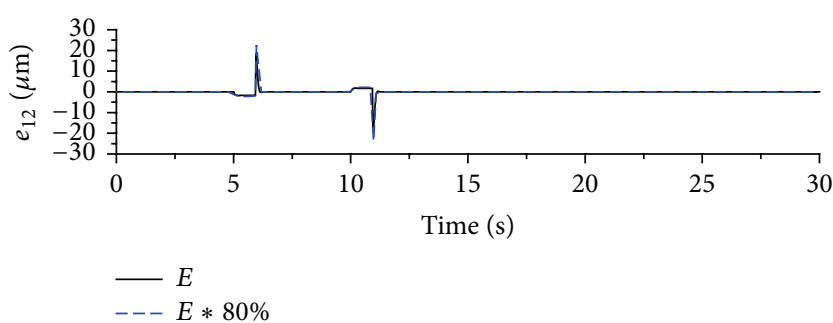

(a) Register error $e_{12}$

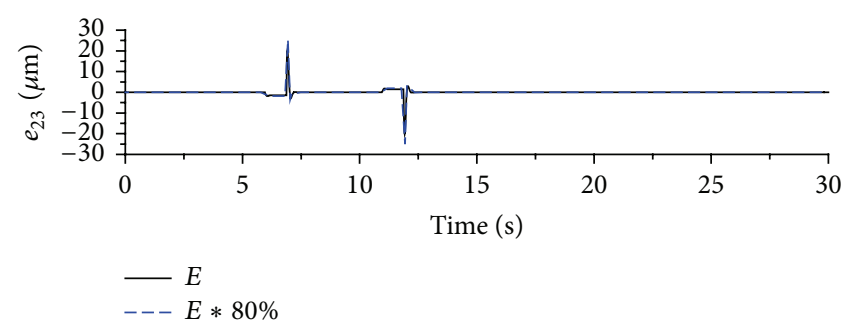

(b) Register error $e_{23}$

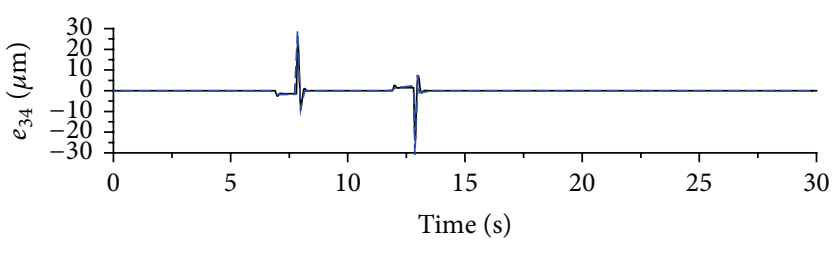

$-E$
$---E * 80 \%$

(c) Register error $e_{34}$

FIgURE 14: Response curves of the ADRC control strategy.
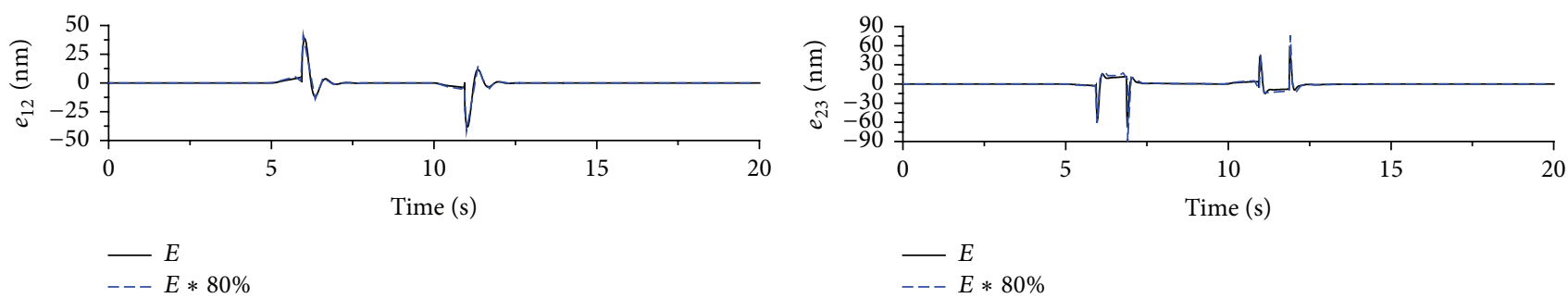

(a) Register error $e_{12}$

(b) Register error $e_{23}$

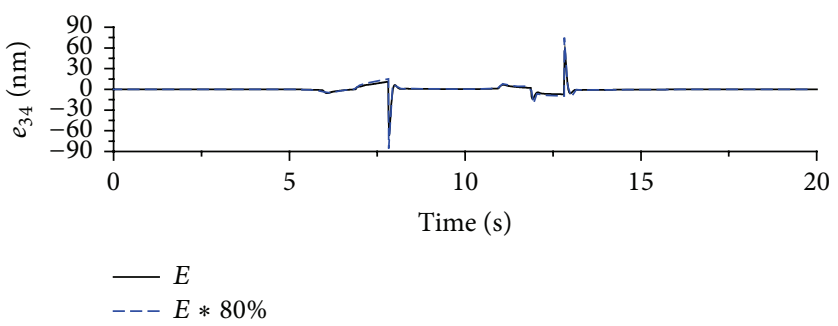

(c) Register error $e_{34}$

FIGURE 15: Response curves of the proposed decoupling control strategy.

for four-layer register system, the simulation results show that, with the disappearance of transient disturbances (for instance the interference of $T_{0}(t)$ in simulation), the outputs of the four-layer register system can return to their original equilibrium state rapidly. In other words, the proposed decoupling control strategy is stable for the four-layer register system. Therefore, this study demonstrates that the proposed strategy is a promising solution for solving the problem of the multilayer register system in R2R gravure printed electronic equipment.

\section{Nomenclature}

$e_{i(i+1)}$ : Register error between $i$ th and $(i+1)$ th printing units $(\mathrm{m})$ $e^{*}: \quad$ Steady-state value of the $e_{i(i+1)}(\mathrm{m})$

$\Delta e_{i(i+1)}$ : Variable value of the $e_{i(i+1)}(\mathrm{m})$

$e_{r i(i+1)}:$ Reference inputs of the $e_{i(i+1)}(\mathrm{m})$

$E_{i(i+1)}(s)$ : Image function of the $e_{i(i+1)}(t)(\mathrm{m})$

$\omega_{i}$ : $\quad$ Angular velocity of the printing cylinder $i$ $(\mathrm{rad} / \mathrm{min})$

$\omega^{*}: \quad$ Steady-state value of the $\omega_{i}(\mathrm{rad} / \mathrm{min})$

$\Delta \omega_{i}: \quad$ Variable value of the $\omega_{i}(\mathrm{rad} / \mathrm{min})$

$W_{i}(s): \quad$ Image function of the $\omega_{i}(t)(\mathrm{rad} / \mathrm{min})$

$R_{i}$ : $\quad$ Radius of the printing cylinder $i$

$T_{0}: \quad$ Web tension of the infeeding unit $(\mathrm{N})$

$T_{i}: \quad$ Web tension in the $i$ th span $(\mathrm{N})$

$T^{*}: \quad$ Steady-state value of the $T_{i}(\mathrm{~N})$

$\Delta T_{i}: \quad$ Variable value of the $T_{i}(\mathrm{~N})$

$T_{i}(s)$ Image function of the $T_{i}(t)(\mathrm{N})$ 
$L_{i}$ : Nominal span length of the web in the $i$ th $\operatorname{span}(\mathrm{m})$

$t_{T i}$ : Transmission time of the web from $i$ th to $(i+1)$ th printing units $(\mathrm{s})$

$E$ : Modulus of elasticity of the web material $(\mathrm{Pa})$

A: Cross-sectional area of the web $\left(\mathrm{m}^{2}\right)$.

\section{Competing Interests}

The authors declare that there is no conflict of interests regarding the publication of this paper.

\section{Acknowledgments}

This project is supported by the National Natural Science Foundation of China (Grant nos. 51505376 and 51305341) and by the Natural Science Basic Research Plan in Shaanxi Province of China (Grant no. 2016JQ5038).

\section{References}

[1] M. Jung, J. Kim, H. Koo, W. Lee, V. Subramanian, and G. Cho, "Roll-to-roll gravure with nanomaterials for printing smart packaging," Journal of Nanoscience and Nanotechnology, vol. 14, no. 2, pp. 1303-1317, 2014.

[2] H.-K. Kang, C.-W. Lee, and K.-H. Shin, "Novel modeling of correlation between two-dimensional registers in large-area multilayered roll-to-roll printed electronics," Japanese Journal of Applied Physics, vol. 50, no. 1, Article ID 016701, 2011.

[3] S. Liu, X. Mei, J. Li, K. He, and Q. Wen, "Design feedforward active disturbance rejection control controller for multi-color register system," Journal of Mechanical Engineering, vol. 51, no. 5, pp. 143-150, 2015.

[4] T. Yoshida, S. Takagi, Y. Muto, and T. Shen, "Modeling and register control of sectional drive gravure printing press," Transactions of the Japan Society of Mechanical Engineers, Part C, vol. 74, no. 6, pp. 1438-1444, 2008.

[5] M. Zhou, Z. Chen, Y. Zheng, and L. Zou, "Model based PD control during the speed-up phase in roll-to-roll web register systems," in Proceedings of the 33rd Chinese Control Conference (CCC '14), pp. 5139-5143, Nanjing, China, July 2014.

[6] J. Li, X. Mei, T. Tao, and S. Liu, "Research on the register system modelling and control of gravure printing press," Proceedings of the Institution of Mechanical Engineers, Part C: Journal of Mechanical Engineering Science, vol. 226, no. 3, pp. 626-635, 2012.

[7] H. Kang, C. Lee, and K. Shin, "Modeling and compensation of the machine directional register in roll-to-roll printing," Control Engineering Practice, vol. 21, no. 5, pp. 645-654, 2013.

[8] Z. Chen, J. He, Y. Zheng, T. Song, and Z. Deng, "An optimized feedforward decoupling PD register control method of Roll-toRoll web printing systems," IEEE Transactions on Automation Science and Engineering, vol. 13, no. 1, pp. 274-283, 2016.

[9] J. Lee, J. Seong, J. Park, S. Park, D. Lee, and K.-H. Shin, "Register control algorithm for high resolution multilayer printing in the roll-to-roll process," Mechanical Systems and Signal Processing, vol. 60, pp. 706-714, 2015.

[10] T. Yoshida, S. Takagi, Y. Muto, and T. Shen, "Register control of rotogravure printing press. Application of nonlinear control theory to sectional drive printing press," Electronics and Communications in Japan, vol. 94, no. 1, pp. 17-24, 2011.

[11] A. Seshadri and P. R. Pagilla, "Decentralized control of print registration in roll-to-roll printing presses," in Proceedings of the ASME Dynamic Systems and Control Conference (DSCC '13), pp. 1-10, Palo Alto, Calif, USA, October 2013.

[12] M. Yang and S. Zhang, "Simulation and research of register control system based on sliding mode variable structure," in Proceedings of the 25th Chinese Control and Decision Conference (CCDC '13), pp. 514-519, Guiyang, China, May 2013.

[13] Y.-J. Chen, Z.-H. Chen, and Z.-H. Deng, "Active disturbance rejection and decoupling control of gravure press register system," Control Theory and Applications, vol. 31, no. 6, pp. 814820, 2014.

[14] C. H. Kim, H.-I. You, and S.-H. Lee, "Register control of roll-to-roll gravure-offset printing equipment considering time difference between measurement and actuation," Proceedings of the Institution of Mechanical Engineers, Part C: Journal of Mechanical Engineering Science, vol. 226, no. 11, pp. 2726-2738, 2012.

[15] C. Kim, H. You, and J. Jo, "Register control of roll-to-roll printing system based on statistical approach," Japanese Journal of Applied Physics, vol. 52, no. 5, pp. 1-5, 2013.

[16] Z. Gao, "Active disturbance rejection control: a paradigm shift in feedback control system design," in Proceedings of the American Control Conference, pp. 2399-2405, Minneapolis, Minn, USA, June 2006.

[17] J. Han, Active Disturbance Rejection Control Technique, National Defence Industry Press, Beijing, China, 2008.

[18] J. Han, "From PID to active disturbance rejection control," IEEE Transactions on Industrial Electronics, vol. 56, no. 3, pp. 900906, 2009.

[19] S. Liu, X. Mei, F. Kong, and K. He, "A decoupling control algorithm for unwinding tension system based on active disturbance rejection control," Mathematical Problems in Engineering, vol. 2013, Article ID 439797, 18 pages, 2013.

[20] Q. Zheng and Z. Gao, "Predictive active disturbance rejection control for processes with time delay," ISA Transactions, vol. 53, no. 4, pp. 873-881, 2014.

[21] D. Li, C. Li, Z. Gao, and Q. Jin, "On active disturbance rejection in temperature regulation of the proton exchange membrane fuel cells," Journal of Power Sources, vol. 283, pp. 452-463, 2015.

[22] G. Liang, W. Li, and Z. Li, "Control of superheated steam temperature in large-capacity generation units based on active disturbance rejection method and distributed control system," Control Engineering Practice, vol. 21, no. 3, pp. 268-285, 2013.

[23] L. Sun, D. Li, K. Hu, K. Y. Lee, and F. Pan, "On tuning and practical implementation of active disturbance rejection controller: a case study from a regenerative heater in a $1000 \mathrm{MW}$ power plant," Industrial \& Engineering Chemistry Research, vol. 55, no. 23, pp. 6686-6695, 2016.

[24] S.-H. Liu, X.-S. Mei, K. He, and J. Li, "Active disturbance rejection decoupling control for multi-color register system in gravure printing machine," Control Theory and Applications, vol. 31, no. 11, pp. 1574-1579, 2014.

[25] S. Liu, X. Mei, J. Li, and L. Ma, "Machine directional register system modeling for shaft-less drive gravure printing machines," Mathematical Problems in Engineering, vol. 2013, Article ID 251636, 10 pages, 2013. 
[26] D. Li, Z. Li, Z. Gao, and Q. Jin, "Active disturbance rejectionbased high-precision temperature control of a semibatch emulsion polymerization reactor," Industrial and Engineering Chemistry Research, vol. 53, no. 8, pp. 3210-3221, 2014.

[27] X. Chen, D. Li, Z. Gao, and C. Wang, "Tuning method for second-order active disturbance rejection control," in Proceedings of the 30th Chinese Control Conference (CCC '11), pp. 63226327, July 2011.

[28] S. Liu, X. Mei, F. Kong, and J. Shen, "Tension controller design for unwinding tension system based on active disturbance rejection control," in Proceedings of the 9th IEEE International Conference on Mechatronics and Automation (ICMA '12), pp. 1798-1803, Chengdu, China, August 2012.

[29] W. Xue and Y. Huang, "On parameters tuning and capability of sampled-data ADRC for nonlinear coupled uncertain systems," in Proceedings of the 32nd Chinese Control Conference, pp. 317321, Xi'an, China, October 2013.

[30] Q. Zheng, L. Q. Gao, and Z. Gao, "On stability analysis of active disturbance rejection control for nonlinear time-varying plants with unknown dynamics," in Proceedings of the 46th IEEE Conference on Decision and Control (CDC '07), pp. 3501-3506, IEEE, New Orleans, La, USA, December 2007.

[31] J. Li, Y. Xia, X. Qi, Z. Gao, K. Chang, and F. Pu, "Absolute stability analysis of non-linear active disturbance rejection control for single-input-single-output systems via the circle criterion method," IET Control Theory \& Applications, vol. 9, no. 15, pp. 2320-2329, 2015.

[32] J. Li, X. Qi, Y. Xia et al., "On asymptotic stability for nonlinear ADRC based control system with application to the ballbeam problem," in Proceedings of the 2016 American Control Conference, pp. 4725-4730, Boston, Mass, USA, July 2016. 


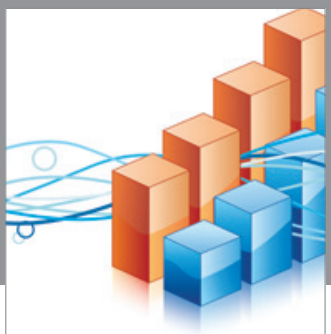

Advances in

Operations Research

vatem alat4

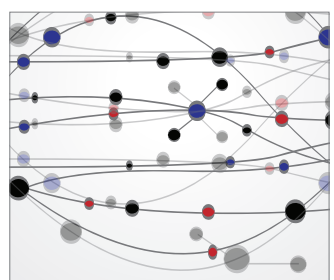

\section{The Scientific} World Journal
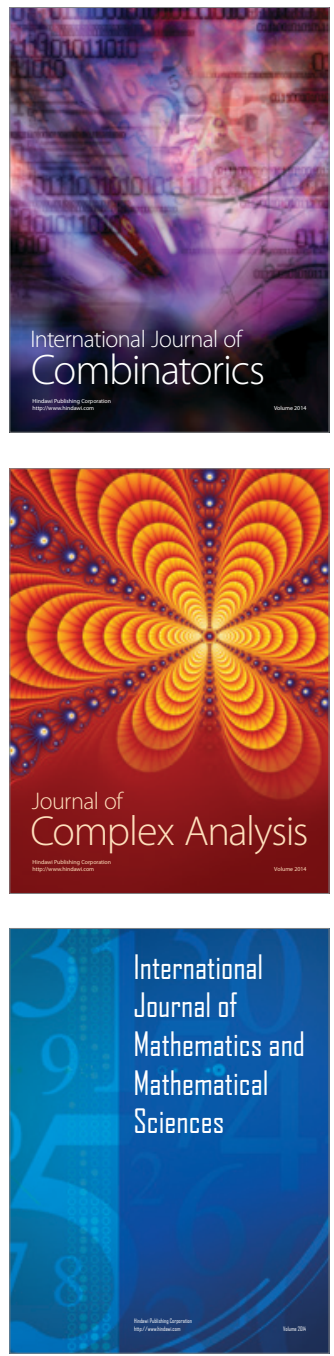
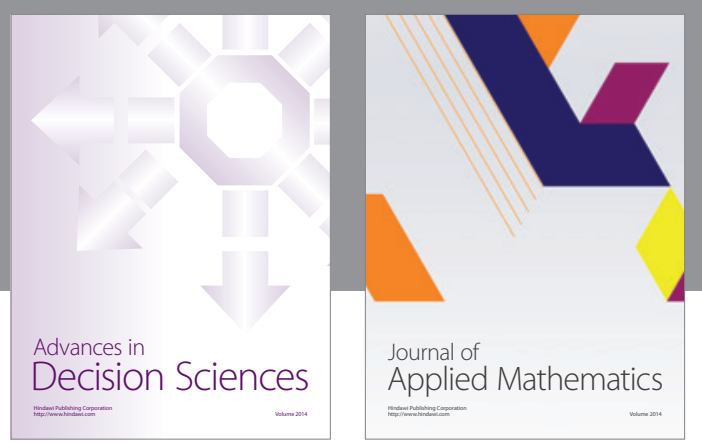

Algebra

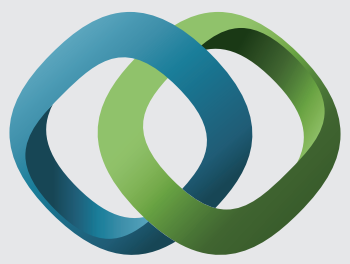

\section{Hindawi}

Submit your manuscripts at

http://www.hindawi.com
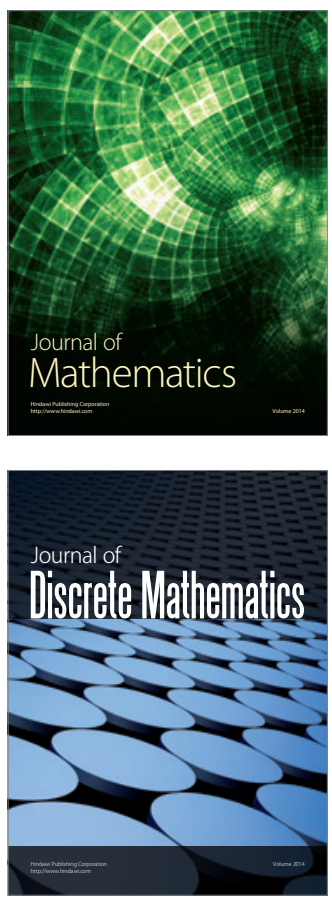

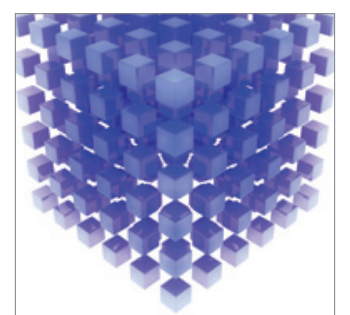

Mathematical Problems in Engineering
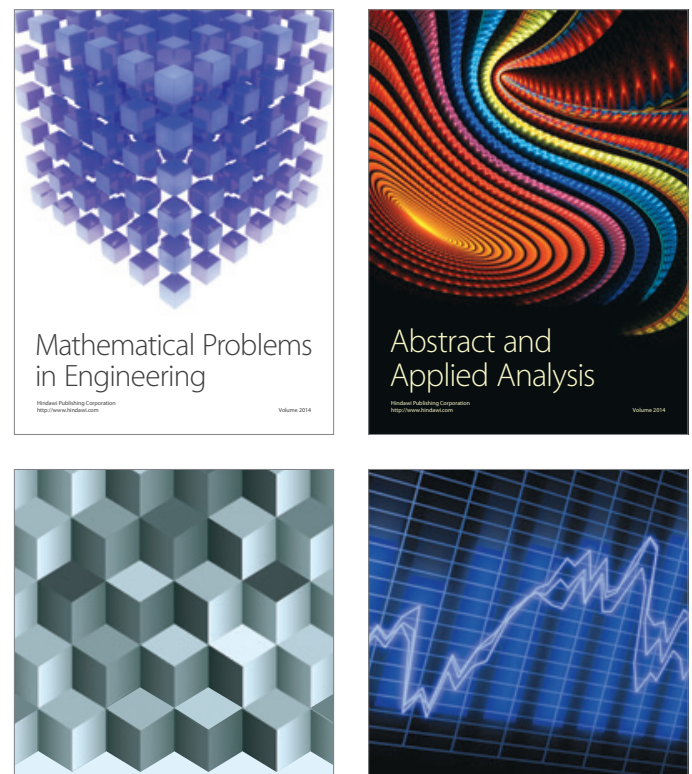

Journal of

Function Spaces

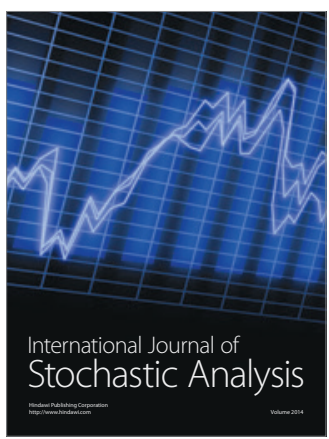

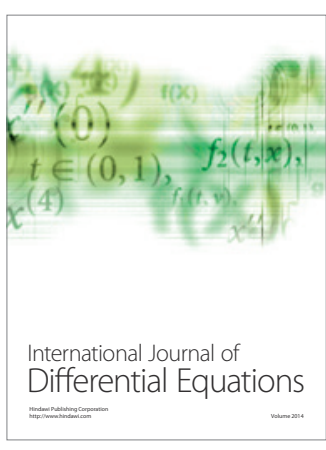
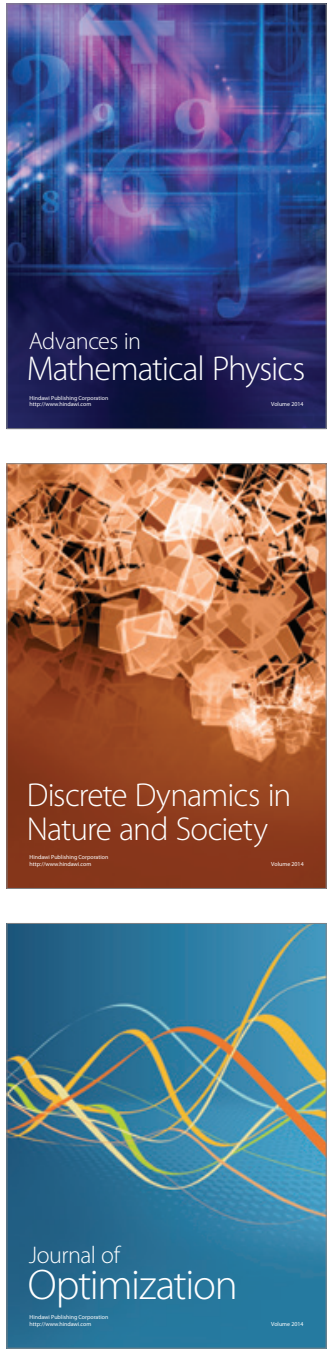